\begin{abstract}
Iranica
Abstracta Iranica Revue bibliographique pour le domaine irano-aryen

Volume 34-35-36 | 2017

Comptes rendus des publications de 2011-2013
\end{abstract}

\title{
Jessica L. Nitschke, S. Rebecca Martin, Yiftah Shalev. Between Carmel and the Sea. Tel Dor: The Late Periods
}

\section{Astrid Nunn}

\section{(2) OpenEdition Journals}

Édition électronique

URL : http://journals.openedition.org/abstractairanica/41559

DOI : 10.4000/abstractairanica.41559

ISSN : 1961-960X

Éditeur :

CNRS (UMR 7528 Mondes iraniens et indiens), Éditions de l'IFRI

\section{Référence électronique}

Astrid Nunn, « Jessica L. Nitschke, S. Rebecca Martin, Yiftah Shalev. Between Carmel and the Sea. Tel Dor: The Late Periods », Abstracta Iranica [En ligne], Volume 34-35-36 | 2017, document 30, mis en ligne le 15 juillet 2016, consulté le 02 octobre 2020. URL : http://journals.openedition.org/abstractairanica/ 41559 ; DOI : https://doi.org/10.4000/abstractairanica.41559

Ce document a été généré automatiquement le 2 octobre 2020.

Tous droits réservés 


\section{Jessica L. Nitschke, S. Rebecca Martin, Yiftah Shalev. Between} Carmel and the Sea. Tel Dor: The Late Periods

Astrid Nunn 


\section{RÉFÉRENCE}

Jessica L. Nitschke, S. Rebecca Martin, Yiftah Shalev. « Between Carmel and the Sea. Tel Dor: The Late Periods ». Near Eastern Archaeology, 74/3, 2011, p. 132-154.

Cet article, publié dans une revue pour le grand public, donne néanmoins un excellent aperçu sur l'histoire et l'archéologie de Tel Dor de l'époque perse à l'époque romaine. Les trois auteurs s'intéressent à l'urbanisme, aux contacts culturels et à la continuité culturelle dans cette cité ouverte à tous les horizons. Le hiatus de 630 à 450 av. J.-C. reste sans explication. La réurbanisation de l'époque perse est surtout d'ordre domestique. Les maisons, ordonnées en insulae et semble-t-il autour d'une place, étaient selon la coutume de l'époque construites en blocs de pierre. Il est possible que les aires construites aient été divisées en aire d'habitation et en aires de travail. Une des maisons était un atelier, où les tissus étaient teints au murex. Aucun centre cultuel n'a été retrouvé. Mais de nombreuses terres cuites et d'autres objets de style levantin, égyptien, chypriote, grécisant ou plus rarement grec étaient d'ordre religieux. Il est intéressant de noter l'existence de 12 tombes de chiens, qui semblent avoir été particulièrement répandues à l'époque achéménide (cf. Abs. Ir. 31, c.r. $\mathrm{n}^{\circ}$ 68). La céramique importée de Grèce ou les monnaies grecques sont des indicateurs économiques. L'aspect politique est outre les liens avec la Phénicie nettement moins évident. Dor a peut-être vraiment appartenu à Sidon, comme le roi sidonien Eshmunazar nous l'indique dans la fameuse inscription sur son sarcophage.

\section{AUTEURS}

\section{ASTRID NUNN}

Université de Munich 